\begin{tabular}{|c|c|c|}
\hline $\begin{array}{l}\text { Jolan Dupont, MD } \\
\text { Gerontology and Geriatrics, Department of Public } \\
\text { Health and Primary Care, KU Leuven; Department } \\
\text { of Geriatric Medicine, University Hospitals Leuven; } \\
\text { Centre for Metabolic Bone Diseases, University } \\
\text { Hospitals Leuven, Leuven, Belgium }\end{array}$ & $\begin{array}{l}\text { Michaël R. Laurent, MD, PhD } \\
\text { Gerontology and Geriatrics, Department of Public } \\
\text { Health and Primary Care, KU Leuven; Centre for } \\
\text { Metabolic Bone Diseases, University Hospitals } \\
\text { Leuven; Department of Geriatric Medicine, Imelda } \\
\text { Hospital, Bonheiden, Belgium }\end{array}$ & $\begin{array}{l}\text { Lenore Dedeyne, MSc } \\
\text { Gerontology and Geriatrics, Department } \\
\text { of Public Health and Primary Care, KU Leuven, } \\
\text { Leuven, Belgium }\end{array}$ \\
\hline $\begin{array}{l}\text { Frank P. Luyten, MD, PhD } \\
\text { Centre for Metabolic Bone Diseases, University } \\
\text { Hospitals Leuven; Skeletal Biology and Tissue } \\
\text { Engineering Centre, Department of Development } \\
\text { and Regeneration, KU Leuven, Leuven, Belgium }\end{array}$ & $\begin{array}{l}\text { Evelien Gielen, MD, PhD } \\
\text { Gerontology and Geriatrics, Department of Public } \\
\text { Health and Primary Care, KU Leuven; Department } \\
\text { of Geriatric Medicine, University Hospitals Leuven; } \\
\text { Centre for Metabolic Bone Diseases, University } \\
\text { Hospitals Leuven, Leuven, Belgium }\end{array}$ & $\begin{array}{l}\text { Marian Dejaeger, MD, PhD } \\
\text { Gerontology and Geriatrics, Department } \\
\text { of Public Health and Primary Care, KU Leuven; } \\
\text { Department of Geriatric Medicine, University Hos- } \\
\text { pitals Leuven; Centre for Metabolic Bone Diseases, } \\
\text { University Hospitals Leuven, Leuven, Belgium }\end{array}$ \\
\hline
\end{tabular}

\title{
Vertebral fractures after denosumab cessation
}

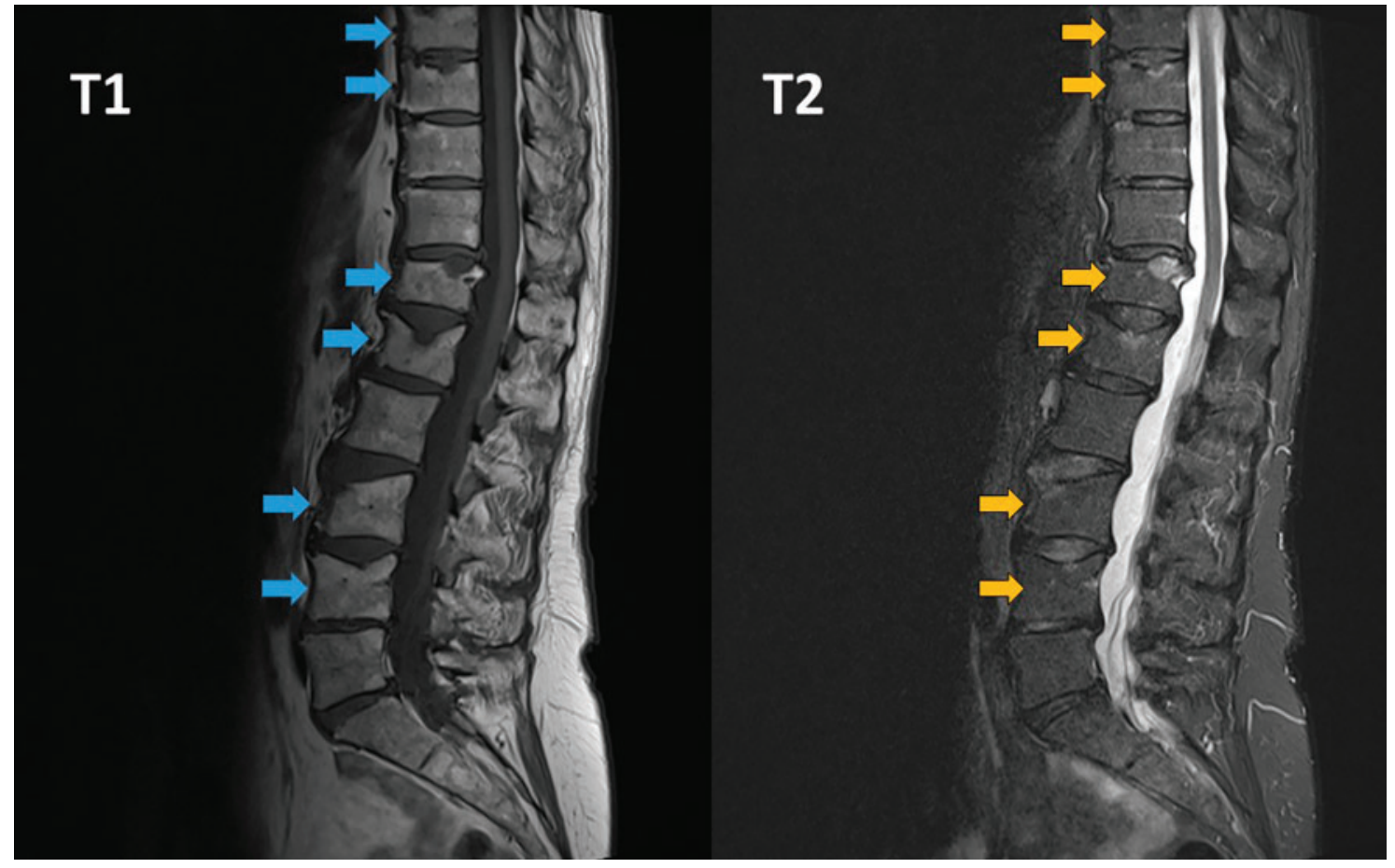

Figure 1. T1-weighted magnetic resonance imaging (left) indicated vertebral fractures of T8, T9, T12, L1, L3, and L4 (arrows). T2-weighting (right) showed bone marrow edema (arrows).

\begin{abstract}
A 63-YEAR-OLD WOMAN presented to the outpatient metabolic bone disease clinic with a 6-month history of lumbar and dorsal back pain. Initially, facet arthrosis was suspected and physical therapy suggested.
\end{abstract}

See related editorial, page 339

Physical therapy for 1 month brought no improvement in her pain. Lumbar radiography was performed, which showed a vertebral doi:10.3949/ccjm.87a.19152 fracture at T12. Magnetic resonance imaging (MRI) of the thoracic and lumbar spine (Figure 1) revealed vertebral fractures at T6, T7, T8, T9, T12, L1, L3, and L4. T2-weighted MRI revealed bone marrow edema, which suggested that all fractures were recent.

The patient had a history of postmenopausal osteoporosis without prior fractures, treated with subcutaneous denosumab injections every 6 months for 5 years. Ten months before the onset of her first symptoms and 16 months before diagnosis of vertebral fractures,
She had a 6-month history of lumbar and dorsal back pain, initially suspected to be facet arthrosis; physical therapy brought no improvement 
denosumab was stopped for a "drug holiday" after 5 years.

There was no imaging available from before the start of denosumab, although computed tomography done for kidney stones 9 months after denosumab cessation showed no lumbar vertebral fractures (thoracic spine not visible on these images). Moreover, her beta-C-terminal telopeptide concentration-a marker of bone turnover-was $852 \mathrm{ng} / \mathrm{L}$ (reference range $104-1,008 \mathrm{ng} / \mathrm{L}$ ) at the time of MRI and diagnosis of vertebral fractures. These findings suggested recent rebound-associated vertebral fractures after denosumab cessation.

\section{REBOUND-ASSOCIATED VERTEBRAL FRACTURE}

Denosumab is a commonly used antiresorptive that increases bone mineral density and reduces the risk of vertebral, nonvertebral, and hip fractures in postmenopausal osteoporosis. It has a reversible effect, and after denosumab cessation, bone turnover markers transiently rebound above baseline levels. ${ }^{1}$

A 2018 post hoc analysis of data from the Fracture Reduction Evaluation of Denosumab in Osteoporosis Every 6 Months (FREEDOM) trial on study participants who discontinued denosumab suggested that the rate of vertebral fracture increased after denosumab cessation to a level comparable with that in untreated patients, ${ }^{2}$ a phenomenon often described as rebound-associated vertebral fracture. ${ }^{3-10}$ In patients who subsequently developed fractures, there was a significant increase in the number of those sustaining multiple vertebral fractures, with previous vertebral fracture being the main risk factor. ${ }^{2}$

Most rebound-associated vertebral fractures occur 2 to 10 months after the effect of the last dose is depleted, ${ }^{2,3}$ as in our patient's case.

There is no optimal management protocol for denosumab cessation based on evidence from randomized controlled trials. Based on current knowledge, it is recommended not to stop denosumab without considering alternative treatments (eg, a potent bisphosphonate) in order to prevent rapid loss of bone mineral density and a potential rebound in vertebral fracture risk. ${ }^{2,11,12}$ Our patient was treated with zoledronate intravenously immediately after diagnosis of the fractures. At most recent follow-up, she has suffered no additional fractures.

\section{REFERENCES}

1. Bone HG, Bolognese MA, Yuen CK, et al. Effects of denosumab treatment and discontinuation on bone mineral density and bone turnover markers in postmenopausal women with low bone mass. J Clin Endocrinol Metab 2011; 96(4):972-980. doi:10.1210/jc.2010-1502

2. Cummings SR, Ferrari S, Eastell R, et al. Vertebral fractures after discontinuation of denosumab: a post hoc analysis of the randomized placebo-controlled FREEDOM trial and its extension. J Bone Miner Res 2018; 33(2):190-198. doi:10.1002/jbmr.3337

3. Anastasilakis AD, Polyzos SA, Makras P, Aubry-Rozier B, Kaouri S, Lamy $\mathbf{O}$. Clinical features of 24 patients with rebound-associated vertebral fractures after denosumab discontinuation: systematic review and additional cases. J Bone Miner Res 2017; 32(6):1291-1296. doi:10.1002/jbmr.3110

4. Dupont J, Laurent MR, Dedeyne L, Luyten FP, Gielen E, Dejaeger M. Rebound-associated vertebral fractures after stopping denosumab: report of four cases. Joint Bone Spine 2020; 87(2):171-173. doi:10.1016/j.jbspin.2019.07.010

5. Aubry-Rozier B, Gonzalez-Rodriguez E, Stoll D, Lamy O. Severe spontaneous vertebral fractures after denosumab discontinuation: three case reports. Osteoporos Int 2016; 27(5):1923-1925. doi:10.1007/s00198-015-3380-y

6. Lamy O, Gonzalez-Rodriguez E, Stoll D, Hans D, Aubry-Rozier B. Severe rebound-associated vertebral fractures after denosumab discontinuation: 9 clinical cases report. J Clin Endocrinol Metab 2017; 102(2):354-358. doi:10.1210/jc.2016-3170
7. Niimi R, Kono T, Nishihara A, Hasegawa M, Kono T, Sudo A. Rebound-associated vertebral fractures after discontinuation of denosumab for the treatment of maxillitis. Osteoporos Int 2018;29(3):769-72. Osteoporos Int 2018; 29(3):769-772. doi:10.1007/s00198-017-4334-3

8. Florez H, Ramirez J, Monegal A, Guanabens N, Peris P. Spontaneous vertebral fractures after denosumab discontinuation: a case collection and review of the literature. Semin Arthritis Rheum 2019; 49(2):197-203. doi:10.1016/j.semarthrit.2019.02.007

9. Polyzos SA, Terpos E. Clinical vertebral fractures following denosumab discontinuation. Endocrine 2016; 54(1):271-272. doi:10.1007/s12020-016-1030-6

10. Tripto-Shkolnik L, Rouach V, Marcus $Y$, Rotman-Pikielny P, Benbassat C, Vered I. Vertebral fractures following denosumab discontinuation in patients with prolonged exposure to bisphosphonates. Calcif Tissue Int 2018; 103(1):44-49. doi:10.1007/s00223-018-0389-1

11. Tsourdi E, Langdahl B, Cohen-Solal M, et al. Discontinuation of denosumab therapy for osteoporosis: a systematic review and position statement by ECTS. Bone 2017; 105:11-17. doi:10.1016/j.bone.2017.08.003

12. Lamy O, Stoll D, Aubry-Rozier B, Rodriguez EG. Stopping denosumab. Curr Osteoporos Rep 2019; 17(1):8-15. doi:10.1007/s11914-019-00502-4

Address: Jolan Dupont, MD, Department of Geriatric Medicine, University Hospitals Leuven, Herestraat 49, PO Box 7003, 3000 Leuven, Belgium; Jolan.dupont@uzleuven.be 